\title{
VARIANT PATTERNS OF BRACHIAL PLEXUS - A CADAVERIC STUDY IN NORTH INDIAN POPULATION
}

\section{Rimple Bansal *1, Rajan Kumar Singla 2, Subhash Kaushal ${ }^{3}$, Apurba Patra 4.}

${ }^{* 1}$ Senior Resident, Department of Anatomy, GMC Patiala, Punjab, India.

${ }^{2}$ Prof.\& Head, Department of Anatomy, GMC Patiala, Punjab, India.

${ }^{3}$ Professor, Department of Anatomy, GMC Patiala, Punjab, India.

${ }^{4}$ Senior Resident, Department of Anatomy, GMC Patiala, Punjab, India.

\section{ABSTRACT}

Background: The brachial plexus is constituted by the ventral rami of C5-T1 spinal nerves. It forms a network of terminal nerves that innervate the upper limb. Variations of brachial plexus are common and a better awareness of variations is very crucial to achieve successful results in its surgical procedures. The aim of present study was to find the variant patterns of brachial plexus and to discuss their developmental and clinical significance.

Materials and Method: 50 upper limbs belonging to 25 formalized and well preserved male cadavers obtained from the Department of Anatomy, constituted the material for the study. These were dissected and roots, trunks, cords and terminal branches of brachial plexus were exposed. The variant patterns were noted and photographed.

Results: Out of 50 limbs, 5 limbs showed variations of brachial plexus at different levels. All the variations seen were unilateral. Out of 5 variant patterns seen, different types of communications between musculocutaneous and median nerve were observed in $4 \mathrm{limbs}(8 \%)$. Out of 4 , in $1 \mathrm{limb}(2 \%)$ medial cord joined with lateral root of median nerve to form mediano-ulnar nerve which after a distance of $1 \mathrm{~cm}$ bifurcated into median and ulnar nerve. In one limb (2\%), there was no distinction between medial and lateral cord. Instead a single anterior cord was formed by union of anterior divisions of all the three trunks anterior to axillary artery.

Conclusion: The variant patterns of brachial plexus are usually more prone to accidental injuries and entrapment neuropathies. Knowledge of such variations may provide additional anatomical information for the clinicians during diagnosis of unusual clinical symptoms and also for surgeons during surgical exploration of axilla and arm to avoid damage to these nerves.

KEY WORDS: Brachial Plexus, anatomical Variations, Lateral Cord, Median Nerve, Two Cords.

Address for Correspondence: Dr. Rimple Bansal, Senior Resident, Department of Anatomy, GMC Patiala, Punjab, India. E-Mail: rimpledr79@gmail.com

Access this Article online

Quick Response code

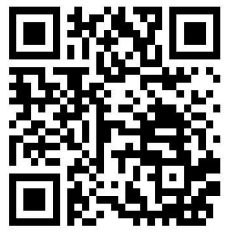

DOI: $10.16965 /$ ijar.2017.532

Journal Information

International Journal of Anatomy and Research

ICV for 2016 ISSN (E) 2321-4287 | ISSN (P) 2321-8967

90.30

https://www.ijmhr.org/ijar.htm

DOI-Prefix: https://dx.doi.org/10.16965/ijar

Article Information

Received: 19 Dec 2017

Peer Review: 19 Dec 2017

Revised: None
Accepted: 02 Feb 2018

Published (O): 05 Mar 2018

Published (P): 05 Mar 2018

\section{INTRODUCTION}

The brachial plexus is constituted by the ventral rami of C5-T1 spinal nerves. It forms a network of nerves innervating the upper limb [1]. The ventral rami of $\mathrm{C} 5$ and $\mathrm{C} 6$ join to form the upper trunk, $\mathrm{C} 7$ continues as middle trunk while inferior trunk is formed by union of $\mathrm{C} 8$ and T1ventral rami[2]. All the three trunks bifurcate into anterior and posterior divisions. The posterior divisions of all the trunks unite together to form the posterior cord. However, the anterior divisions of the upper and middle trunks unite to shape lateral cord and anterior division of inferior trunk continues to form the medial cord. The peripheral nerves emanate from these cords[2-4]. 
It must be noted that the brachial plexus is merely a routing mechanism to get nerves with a common function in the proper terminal nerves. The errors in distribution may creep in that are corrected distally in the arm, forearm or hand, resulting in anatomical variations of plexus [5]. Variations in the formation, course and distribution of brachial plexus and its branches have been reported earlier by many authors like Kerr [6], Linell [7] and Adachi [8]. These may present clinically or be observed at surgery, autopsy or cadaveric dissections.

Nowadays, the anaesthetic implications such as blockages at different levels of brachial plexus ( interscalene, infraclavicular, supraclavicular and axillary ) are used in different surgeries on shoulder, elbow, arm, forearm or hand or postoperative analgesia such as shoulder arthroplasty. A better understanding of brachial plexus variations may lead to facilitated nerve blockage [9]. Some variations are vulnerable to get damaged in radical neck dissection and other surgical operations of axilla and upper arm. So this study was conducted to find the variant patterns of brachial plexus and to discuss their developmental and clinical significance.

\section{MATERIALS AND METHODS}

The present study was conducted on 50 upper limbs belonging to 25 formalized and well preserved male cadavers obtained from the Department of Anatomy, Government Medical College, Patiala, Punjab. These limbs were labelled from 1-25 with letters $R$ or $L$ representing right or left sided limbs.The brachial plexus was dissected and exposed as per dissection guidelines given by Cunningham's manual of practical Anatomy [10]. All the roots, trunks, divisions, cords and branches were cleaned and the pattern of formation and branching was seen. Variations so obtained were noted and photographs were taken.

\section{OBSERVATIONS}

Out of 50 limbs, the brachial plexus were found to be normal in 45 limbs (90\%) regarding its formation and branching pattern while 5 limbs (10\%) showed variations at different levels. All the variations seen were unilateral, 3 belonging to right side and 2 to the left side. These were as follows:
1. In limb no. 5R, the medial cord did not give the ulnar nerve. Instead after giving medial pectoral, medial cutaneous nerve of arm and medial cutaneous nerve of forearm, it joined with lateral root of median nerve to form medianoulnar nerve anteromedial to axillary artery. The medianoulnar nerve thus formed continued for a distance of $1 \mathrm{~cm}$ and bifurcated into median nerve and ulnar nerve. The rest of the course of ulnar nerve was normal. Musculocutaneous nerve had a normal origin but instead of piercing the coracobrachialis it gave a branch to the same and one branch to biceps.Then it joined with the median nerve in the middle of arm. The rest of branches of musculocutaneous nerve came from median nerve. [Fig 1]

2. In two limbs (10L \& 14L), Musculocutaneous nerve gave a communicating ramus (CR) to median nerve before piercing the coracobrachialis. Thus median nerve was formed by three roots 1. Medial root 2. Lateral root 3. A Communicating ramus from musculocutaneous nerve. All the flexor muscles of arm were supplied by musculocutaneous nerve. [Fig 2]

3. In one limb (21R) Musculocutaneous nerve was absent in axilla. Lateral cord gave a branch to coracobrachialis and the continued as lateral root which fused with the medial root to form the median nerve anterior to axillary artery. Then later ran about $1.5 \mathrm{~cm}$ anterior to artery and left the axilla. In the middle of arm it bifurcated into lateral and medial branches which behaved as musculocutaneous and median nerve respectively. [Fig 3] All the flexor muscles of arm except corachobrachialis were supplied by lateral brach i.e. musculocutaneous nerve.

4. In $20 \mathrm{R}$, there was no distinction between medial and lateral cord. Instead a single anterior cord was formed by union of anterior divisions of upper, middle and lower trunks in front of $2^{\text {nd }}$ part of axillary artery. This anterior division gave from lateral to medially musculocutaneous, lateral and medial root of median and ulnar nerve. Both the roots of median nerve fused at the lower border of teres major to form the median nerve, but lateral root before joining with the medial root gave muscular branches for biceps. [Fig 4]

In this study most of the variations seen in different parts of brachial plexus belonged to 
Fig. 1: Showing Mediano-ulnar Nerve \& Type V(B) communication between Musculocutaneous and Median Nerve. (AA-Axillary Artery,BB-Biceps Brachii,CBCorachobrachialis,D-Distal,L-Lateral,LC-Lateral Cord,LRLateral Root,M-Medial,MC-Medial Cord,MN-Median Nerve, MCN-Musculocutaneous Nerve,P-Proximal)

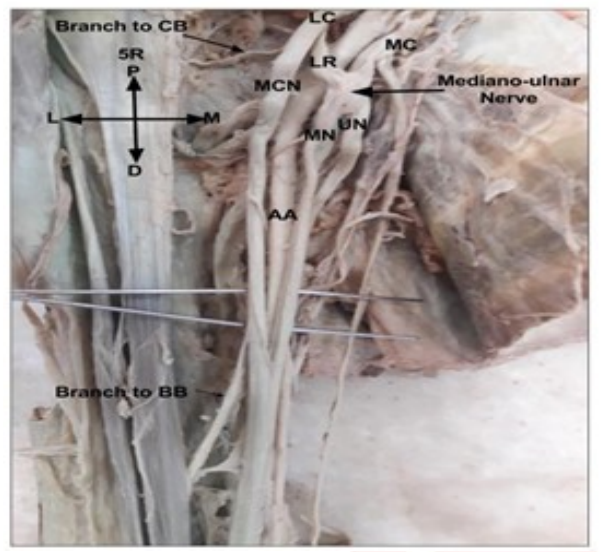

Fig. 2: Showing Type II(B) communication between Musculocutaneous and Median Nerve. (AA-Axillary Artery, CB-Corachobrachialis, CR-Communicating Ramus,D-Distal,L-Lateral,LC-Lateral Cord,LR-Lateral Root,M-Medial,MN-Median Nerve,MCN-Musculocutaneous Nerve,P-Proximal)

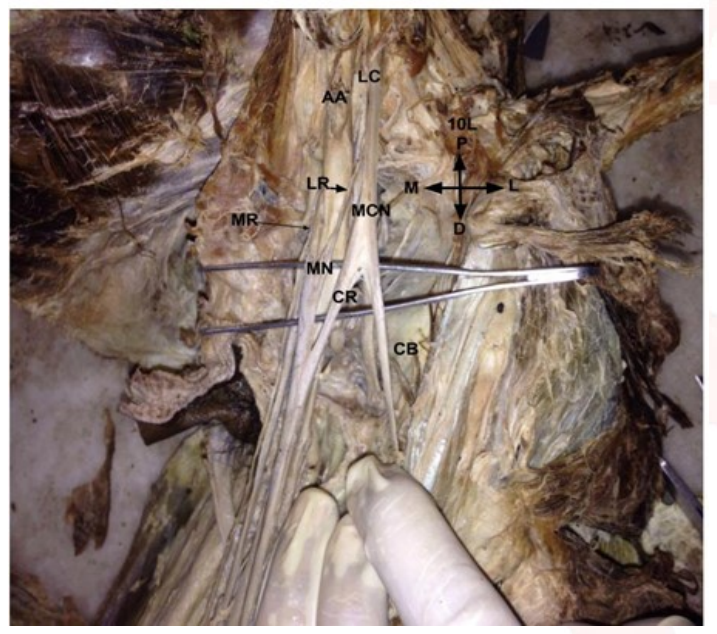

Fig. 3: Showing Type IV(A) communication between Musculocutaneous and Median Nerve. (AA-Axillary Artery, CB-Corachobrachialis, D-Distal,L-Lateral, LC-Lateral Cord,LR-Lateral Root,M-Medial,MN-Median Nerve,P-Proximal)

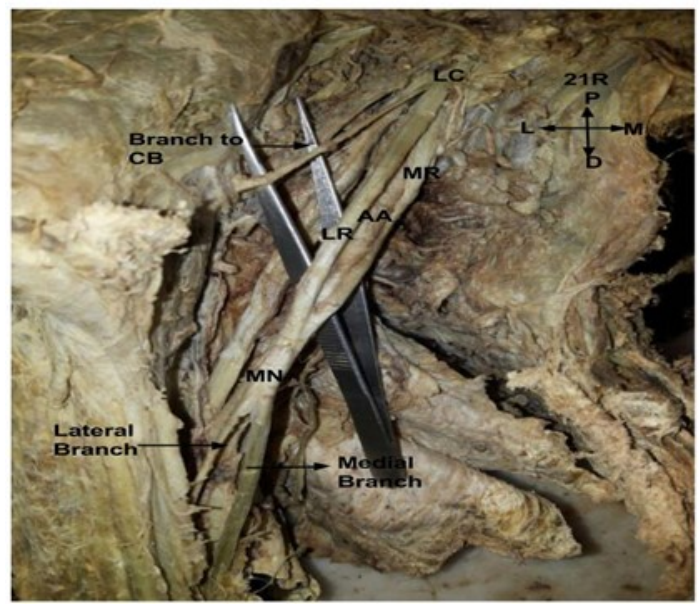

Fig. 4: Showing Two Cords of Brachial Plexus (AA-Axillary Artery, AC-Anterior Cord, D-Distal,L-Lateral,LR-Lateral Root,M-Medial,MN-Median Nerve, MR- Medial Root, MCN-Musculocutaneous Nerve, UN- Ulnar Nerve, P-Proximal)

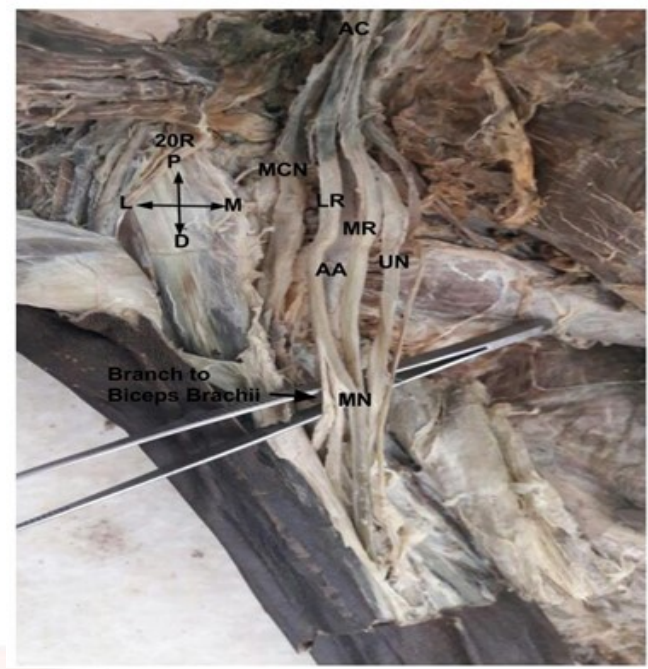

the terminal branches. Out of 5 variant patterns seen, different types of communications between musculocutaneous and median nerve were observed in 4 limbs (8\%) while in 1 limb (2\%) two cords of brachial plexus ie anterior and posterior cords were found.

\section{DISCUSSION}

Variations in the origin of the median and musculocutaneous nerve are quite common. The commonest amongst these is the absence of musculocutaneous nerve with innervation of coracobrachialis, biceps brachii and brachialis by median nerve [Li Minor, [11]; Rao and Chaudhary, [12]; Rajashree et al, [13] ; Saritha,[14] and Chaudhary et al, [15]. But in the current study, none of the limb showed absence of musculocataneous nerve. However, in one limb (21R) musculocutaneous nerve was not seen in axilla. Lateral cord gave a branch to coracobrachialis and the continued as lateral root which fused with the medial root to form the median nerve anterior to axillary artery. In the middle of arm it bifurcated into lateral and medial branch which behaved as musculocutaneous and median nerve respectively. Here the biceps brachii and brachialis were supplied by lateral branch i.e. musculocutaneous nerve.

Another variation is communication between musculocutaneous nerve and median nerve. Venieratos and Anangnostopoulou [16] believed it to be the most frequent variant of this nerve where some fibers of the lateral root of the 
median nerve run along with the musculocutaneous nerve and after travelling some distance, leave the latter to join the ultimate destination (the median nerve). Communication between musculocutaneous and median nerve has been reported to seen with an incidence varying between $10 \%-33.3 \%$

Table 1: Incidence of communication between the Musculocutaneous Nerve and Median Nerve.

\begin{tabular}{|c|c|c|c|}
\hline S. no & Author & Year & $\begin{array}{c}\text { Incidence } \\
(\%)\end{array}$ \\
\hline $\mathbf{1}$ & Kosugi et al [17] & 1986 & 21.8 \\
\hline $\mathbf{2}$ & Yang et al[18] & 1995 & 12.5 \\
\hline $\mathbf{3}$ & $\begin{array}{c}\text { Venieratos and } \\
\text { Anagnostopoulou[16] }\end{array}$ & 1998 & 13.9 \\
\hline $\mathbf{4}$ & Rao and Chaudhary[12] & 2000 & 33.3 \\
\hline $\mathbf{5}$ & Choi et al[19] & 2002 & 26.4 \\
\hline $\mathbf{6}$ & Kaur and Singla[20] & 2013 & 11.7 \\
\hline $\mathbf{7}$ & Chaudhary et al[15] & 2014 & 10 \\
\hline $\mathbf{8}$ & Present study & 2017 & 8 \\
\hline
\end{tabular}

Such a wide discripency in its incidence may be attributed to the fact that different types of classifications have been provided by earlier workers (Kosugi [17], Romanes[10], Venieratos and Anagnostopoulou[16] and Li Minor[11]. But in 2013 Kaur and Singla compiled these classifications and provided Kaur and Singla classification which is the latest one. According to it the communication between musculocutaneous and median nerve are classified into 6 types as follows:

Type I- No communication.

Type II-Some fibres of lateral root of median nerve pass through musculocutaneous nerve and join the median nerve at different levels in the form of communicating ramus.

Group A- A communicating ramus leaves musculocutaneous nerve immediately after the later is formed so that it gives appearance of trifurcation of lateral cord into a musculocutaneous nerve and two lateral roots.

Group B- The communicating ramus leaves musculocutaneous nerve before it pierces coracobrachialis (All flexor muscles supplied by musculocutaneous nerve)

Group C- The communicating ramus leaves musculocutaneous nerve after it has pierced coracobrachialis. (All flexor muscles supplied by musculocutaneous nerve before the origin of communicating ramus)

Int J Anat Res 2018, 6(1.3):4987-93. ISSN 2321-4287
Type III- All fibres of lateral root of median nerve pass with musculocutaneous nerve. The median nerve is just continuation of medial root only. However the musculocutaneous nerve after supplying flexors of forearm gives lateral root of median nerve to join the same. In other words the lateral root arises distal to origin of muscular branches from musculocutaneous nerve.

Type IV- Whole of lateral cord continues as lateral root of median nerve i.e. musculocutaneous nerve joins lateral root of median nerve and after some distance musculocutaneous nerve arises from the median nerve.

Group A- Musculocutaneous nerve arises from median nerve proximal to muscular branches for flexors of arm which are thus supplied by musculocutaneous nerve.

Group B- Musculocutaneous nerve arises from median nerve after the former had supplied muscles of forearm.Then the musculocutaneous nerve continues only as lateral cutaneous nerve of forearm.

Type V- Complete fusion of musculocutaneous and median nerve at different levels.

Group A-Musculocutaneous nerve is altogether absent with all its fibres passing through lateral root of median nerve.All branches of musculocutaneous nerve come from median nerve.

Group B- Musculocutaneous nerve supplies coracobrachialis and then completely fuses with median nerve. Rest of its branches come from median nerve.

Group C- Musculocutaneous nerve supplies all flexors of arm and then fuses with median nerve. The lateral cutaneous nerve of forearm comes from median nerve.

Type VI- The communicating ramus arises in lower one-third of arm after musculocutaneous nerve has supplied all flexors of arm.lt crosses the elbow joint and reaches forearm where it joins median nerve.

Group A- The communicating ramus joins median nerve without piercing pronator teres.

Group B- The communicating ramus joins median nerve after piercing pronator teres According to this classification the 50 limbs of the present study can be grouped as shown in Tab2. 
Table 2: Showing grouping of limbs of present study according to Kaur and Singla classification.

\begin{tabular}{|c|c|c|c|}
\hline S. no & $\begin{array}{c}\text { No. Of limbs } \\
\text { (\%age) }\end{array}$ & Limb no. & Type \\
\hline 1 & $46(92 \%)$ & - & $\mathrm{I}$ \\
\hline 2 & $2(4 \%)$ & $10 \mathrm{~L}, 14 \mathrm{~L}$ & $\mathrm{II}(\mathrm{B})$ \\
\hline 3 & $1(2 \%)$ & $21 \mathrm{R}$ & $\mathrm{IV}(\mathrm{A})^{*}$ \\
\hline 4 & $1(2 \%)$ & $5 \mathrm{R}$ & $\mathrm{V}(\mathrm{B})^{* *}$ \\
\hline
\end{tabular}

*However in present case corachobrachialis was supplied by a branch from lateral cord.

**However in the present case medial root of median nerve also contained fibres of ulnar nerve so as to form medianoulnar nerve. Later on ulnar nerve emanated from the same. Also musculocutaneous nerve before uniting with median nerve gave branches to corachobrachialis and biceps brachii.

Thus two limbs of present study ( $5 R \& 21 R$ ) partially fit in Kaur \& Singla classification with slight differences. In limb no 5R, medial cord joined with lateral root of median nerve to form mediano-ulnar nerve which after a distance of $1 \mathrm{~cm}$ bifurcated into median and ulnar nerve. So the fibres of $\mathrm{C} 7$ seemed to be distributed through lateral root to ulnar nerve.Such type of communication is a rare finding of brachial plexus though reported earlier by Gopal et al[21].

In limb no 20R, there was no distinction between medial and lateral cord. Instead a single anterior cord was formed by union of anterior divisions of all the three trunks anterior to axillary artery. Kerr[6] reported the same finding in 3 brachial plexus. But the uniqueness of current case is that anterior cord gave rise to both medial and lateral roots of median nerve which then joined to form the median nerve, but before joining with medial root,lateral root gave muscular branches for biceps.Corachobrachialis and brachialis were supplied by musculocutaneous nerve.

Table 3: Comparison of present study with Kaur and Singla.

\begin{tabular}{|c|c|c|c|}
\hline S. no & Type & $\begin{array}{c}\text { Present } \\
\text { study }\end{array}$ & $\begin{array}{c}\text { Kaur and } \\
\text { Singla }\end{array}$ \\
\hline $\mathbf{1}$ & $\mathrm{I}$ & $92 \%$ & $88.30 \%$ \\
\hline $\mathbf{2}$ & $\mathrm{II}(\mathrm{A})$ & & $3.30 \%$ \\
\hline $\mathbf{3}$ & $\mathrm{II}(\mathrm{B})$ & $4 \%$ & $1.66 \%$ \\
\hline $\mathbf{4}$ & $\mathrm{II}(\mathrm{C})$ & & $1.66 \%$ \\
\hline $\mathbf{5}$ & $\mathrm{IV}(\mathrm{A})$ & $2 \%$ & - \\
\hline $\mathbf{6}$ & $\mathrm{V}(\mathrm{A})$ & & $1.66 \%$ \\
\hline $\mathbf{7}$ & $\mathrm{V}(\mathrm{B})$ & $2 \%$ & $1.66 \%$ \\
\hline $\mathbf{8}$ & $\mathrm{VI}(\mathrm{B})$ & & $1.66 \%$ \\
\hline
\end{tabular}

Int J Anat Res 2018, 6(1.3):4987-93. ISSN 2321-4287
Table 3 compares the results of present study with that of Kaur and Singla. Both the studies depict almost similar results with some types of Kaur and Singla not seen in the present study. It could be attributed to the smaller data base of the present study.

Ontogeny: Anomolous pattern of brachial plexus can be explained by Sannes[22] et al that the guidance of the developing axons is regulated by expression of chemoattractants and chemorepulsants in highly coordinated site specific fashion. Any alterations in signalling between mesenchymal cells and neuronal growth cones can lead to significant variations.Once formed, any developmental differences would persist postnatally.

Phylogeny: Chauhan and Roy[23] strongly recommended the consideration of the phylogeny and the development of the nerves of the upper limb for the interpretation of the nerve anomalies of the arm.In dogs, the musculocutaneous nerve sends a communicating branch to the median nerve.Sisson and Grossman, [24]. It was seen in 4 variant limbs of the present study. Miller [25] summarized the work which was done by earlier authors on the brachial plexus in amphibians, reptiles, birds, monotremes, dogs, lemurs, primates in general and in anthropoid apes. He observed that only two cordsanterior and posterior, are seen in birds because the birds possess very little real forearm and hand structures. The ulnar nerve and $\mathrm{MN}$ are undifferentiated and a single nerve trunk supplies the region in the wings of birds. With progressively greater development in shoulder musculature and forearm and hand muscles, formation of 3 cords-medial and lateral cords anteriorly and a single cord posteriorly, has been observed in marsupials, lemurs and monkeys. The anterior cords however undergo fusion to give rise to $\mathrm{MN}$ and ulnar nerve. Thus, separation of nerves appear s more definitely with increase in development of hand and finer muscle co-ordination. The complete separation of medial and lateral cords with ulnar nerve being a product of medial cord only is characteristically evident in man.

Clinical significance: Anatomical variations of infraclavicular part of brachial plexus acquire clinical importance in post traumatic evaluation 
and exploratory interventions of arm for peripheral nerve repair.Moreover, some variations, surprisingly, cause damage of plexus following radical neck dissection and other surgical operations of axilla and upper arm. The presence of communicating branches can be of importance in the evaluation of unexplained sensory loss after trauma or surgical intervention in a particular region. Communication of lateral root with ulnar nerve as seen in present study is a rare finding of brachial plexus. These communications could complicate the management of regional pain syndrome because the sympathetic innervations of upper limb is carried by the fibres of median and ulnar nerves[26].

\section{CONCLUSION}

Out of 5 variant patterns seen, different types of communications between musculocutaneous and median nerve were observed in 4 limbs (8\%).Out of 4, in 1 limb (2\%) medial cord joined with lateral root of median nerve to form mediano-ulnar nerve which after a distance of $1 \mathrm{~cm}$ bifurcated into median and ulnar nerve.This shows the origin of $\mathrm{c} 7$ root of ulnar nerve from lateral cord through lateral root of median nerve.In one limb (2\%), there was no distinction between medial and lateral cord. Instead a single anterior cord was formed by union of anterior divisions of all the three trunks anterior to axillary artery.These variants are usually more prone to accidental injuries and entrapment neuropathies. Knowledge of such variations may provide additional anatomical information for the clinicians during diagnosis of unusual clinical symptoms and also for surgeons during surgical exploration of axilla and arm to avoid damage to these nerves.

\section{Conflicts of Interests: None}

\section{REFERENCES}

[1]. Berry MM, Standring SM, Bannister LH. Nervous system. In: Gray's Anatomy. Edrs.Williams PL, Bannister LH, Berry MM, Collins P, Dyson M, Dussek JE et al. $38^{\text {th }}$ ed. Edinburgh,Churchill Livingstone;1995. pp. 1266-74.

[2]. Orebaugh SL, Williams BA. Brachial plexus anatomy: normal and variant. Sci World J.2009;9:300-12.

[3]. Snell RS. Clinical Anatomy. $7^{\text {th }}$ ed. Philadelphia: Lippincott Williams and Wilkins; 2004.p. 477.

[4]. Hollinshead W. General survey of the upper limbthe back and limbs. In: Anatomy for Surgeons. New York: Hoeber-Harper; 1958. pp. 225-8.
[6]. Kerr AT. The brachial plexus of nerves in man, the variations in its formation and branches.Am J Anat.1918; 23(2): 285-395.

[7]. Linell EA. The distribution of nerves in the upper limb, with reference to variabilities and their clinical significance.J Anat.1921; 55: 79-112.

[8]. Nakatani T, Tanaka S. Absence of the musculocutaneous nerve with innervation of corocobrachialis, biceps brachii, brachialis and the lateral border of the forearm by branches from the lateral cord of the brachial plexus.J Anat.1997; 49: 459-60.

[9]. Emamhadi M, Chabok S, Samini F, Alijani B, Behzadnia $\mathrm{H}$, Firozabadi $\mathrm{F}$ et al. Anatomical Variations of Brachial Plexus in Adult Cadavers; A Descriptive Study. Arch Bone Jt Surg. 2016; 4(3): 253-8.

[10]. Romanes GJ. The pectoral region and axilla, the arm and the forearm and hand. In:Cunninghams Manual of practical Anatomy.vol $1.15^{\text {th }}$ edn Edinburgh,London:The English Language Book Society and Oxford University Press. 1986: 28-89.

[11]. Li Minor JM. A rare variant of median and musculocutaneous nerves in man. Arch Anat Histo Embryol. 1992; 73: 33-42.

[12]. Rao PVVP, Chaudhary SC. Communication of the musculocutaneous nerve with the median nerve. East Afr Med J 2000;77(9):498-503.

[13]. Rajashree B, Arati D, Mamata S, Chinmayi M, Charulata S. Absence of musculocutaneous nerve a case report. J Anat Soc India 2003;52(1):94.

[14]. Saritha S. Variations in the median and musculocutaneous nerves-A surgical prospective. J Anat Soc Ind 2004; 53(1):31-66.

[15]. Chaudhary P, Kalsey G, Singla R, Arora K. Communication Between Musculocutaneous and Median Nerve-Different Types and their incidence in North Indian Population. Ind J of Clin Pract. 2014;25(1):6370.

[16]. Venieratos D, Anagnostopoulou S. Classification of communications between the musculocutaneous and median nerves. Clin Anat.1998;11: 327-31.

[17]. Kosugi K, Mortia T, Yamashita H. Branching pattern of musculocutaneous nerve - Cases possessing normal biceps brachii.Jikeikai Med J.1986;33: 63-71.

[18]. Yang ZX, Pho RWH, Kour AK, Pereira BP. The musculocutaneous nerve and its branches to the biceps and brachialis muscle. J Hand Surg.1995; 20A(4): 671-5.

[19]. Choi D, Niedenfu Venieratos.hr MR, Vazquez T, Parkin I, Sanudo JR. Patterns of connections between the muculocutaneous and median nerve in the axilla and arm.Clin Anat.2002; 15:11-7.

[20]. Kaur N and Singla RK. Different types of communications between musculocutaneous nerve and median nerve- A Cadaveric Study in North Indian Population.Cibtech J Surg.2013;2(1):21-8.

[21]. Gopal K, Anurag, Singh O. Anatomical variations of brachial plexus: anomalous branching pattern.Int J Res Med Sci.2016;4(8):3376-80.

[22]. Sannes HD, Rey TA, Harris W. Axon growth and guidance. New York: Academic Press; 2000. pp. 189-97. 
[23]. Rao PVVP, Chaudhary SC. Communication of the musculocutaneous nerve with the median nerve.East African Med J.2000;77(9): 498-503.

[24]. Sisson S, Grossman JD .In: Anatomy of the domestic animals.4th edi London: Charles E. Tuttle;1961: 83575. Cited by Rao PVVP, Chaudhary SC. Communication of the musculocutaneous nerve with the median nerve.East African Med J.2000;77(9): 498-503.
[[25]. Miller RA. Comparative studies upon the morphology and distribution of the brachial plexus. Am J Anat. 1934;54:143-75.

26]. Pick J. The autonomic nervous system.In: Morphological comparative, clinical and surgical alternate sympathetic pathways. Philadelphia, JB.Lippincott;1970.p

How to cite this article:

Rimple Bansal, Rajan Kumar Singla, Subhash Kaushal, Apurba

Patra. VARIANT PATTERNS OF BRACHIAL PLEXUS - A CADAVERIC

STUDY IN NORTH INDIAN POPULATION. Int J Anat Res 2018;6(1.3):4987-4993. DOI: 10.16965/ijar.2017.532 